The Impact of Affect Phobia Therapy (APT) on Alcohol Use Disorders (AUD)-Evaluating Three Case Studies K.A.R. Osborn

Pragmatic Case Studies in Psychotherapy, http://pcsp.libraries.rutgers.edu

Volume 15, Module 3, Article 2, pp. 258-271, 01-09-20 [copyright by author]

Commentary on: Affect Phobia Therapy for Mild to Moderate Alcohol Use Disorder: The Cases of "Carey," "Michelle," and "Mary"

\title{
The Impact of Affect Phobia Therapy (APT) on Alcohol Use Disorders (AUD)_Evaluating Three Case Studies
}

\author{
KRISTIN A.R. OSBORN ${ }^{\text {a,b }}$ \\ ${ }^{a}$ Department of Psychiatry, Harvard Medical School, Boston, MA; Strategic Psychotherapeutics, LLC, \\ Glastonbury, CT; and Kaizen Brain Center, LaJolla, CA \\ ${ }^{\mathrm{b}}$ Correspondence regarding this article should be sent to Kristin A.R. Osborn, Endeavor Psychology, 10 Newbury \\ Street, 4th Floor, Boston, MA 02116 \\ Email: kristin@kristinosborn.com \\ Editor's Note: Kristin A. R. Osborn is an internationally prominent Affect Phobia Therapy (APT) psychotherapist, \\ trainer, researcher, and author (https://www.affectphobiatherapy.com/kristin-osborn/). Among other positions, she is \\ currently an Associate in Psychiatry at Harvard Medical School. She is the founder of Certified APT TM Training, a \\ rigorous evidence-based program that teaches how to assess and resolve affect phobias \\ (https://www.affectphobiatherapy.com/certified-apt-training-program-overview/). Osborn's particular focus is on \\ moment-to-moment affects in therapy process and the interplay between therapist and patient, as reflected in her co- \\ authored book, Paraverbal Communication in Psychotherapy: Beyond the Words (2016).
}

\begin{abstract}
In this commentary on the important cases of "Carey," "Michelle," and "Mary" conducted by Dr. My Frankl (Frankl, Wennberg, Berggraf, \& Philips, 2020), I begin with some general considerations on the importance of assessment and case formulation in Affect Phobia Therapy (APT) and how these considerations impact on the experiential interventions of APT. Next I specifically review Frankl's three case studies, with a focus on: how Alcohol Use Disorder (AUD) is embedded in close family relationships; the connection between AUD and affect regulation; the role of feelings of shame in AUD; individualizing and adjusting APT treatment based on feedback from ongoing therapy; Frankl's activation of transference feelings; the issue of sobriety before treatment; activating inhibitory affects and maladaptive defenses; Frankl's missing some moments of connection; and an example of Frankl's conducting the two-chair technique skillfully and successfully. I end with a proposal for enhancing Frankl's narrative analysis with two methodologies from APT: the "Ten-Session Summary Form," and the microanalytic coding approach of the "Achievement of Therapeutic Objectives Scales" (ATOS).
\end{abstract}

Key words: Affect Phobia (APT); Affect Phobia; Alcohol Use disorder (AUD)Focused Therapy; ShortTerm Psychodynamic Psychotherapy; emotional avoidance; case studies; clinical case studies.

\section{THE LARGER CONTEXT: THE IMPORTANCE OF ASSESSMENT AND CASE FORMULATION IN APT}

As context to my reflections on Dr. My Frankl's (Frankl, Wennberg, Berggraf, \& Philips 2020) three case studies of "Carey," "Michelle," and "Mary," I begin this commentary with 
The Impact of Affect Phobia Therapy (APT) on Alcohol Use Disorders (AUD)-Evaluating Three Case Studies K.A.R. Osborn

Pragmatic Case Studies in Psychotherapy, http://pcsp.libraries.rutgers.edu

Volume 15, Module 3, Article 2, pp. 258-271, 01-09-20 [copyright by author]

some general comments about the importance of assessment and case formulation in Affect Phobia Therapy (APT). Assessment in APT is key in treating patients with Alcohol Use Disorders (AUD), as the drinking is not necessarily always operating as a maladaptive defense, although the consequences of drinking too much can result in maladaptive behaviors, thoughts, and feelings that present as symptoms for treatment.

Clinicians need to ask themselves and their patients, what is the function of the patient's drinking? What is the patient getting out of it? Is it to regulate anxiety? To block painful feelings? To find the courage to approach a potential lover? Once a clinician and patient can understand how the behavior is functioning, then they can begin to address the underlying issues. What is the drinking providing them and is there a better way? Sometimes it's helpful to keep in mind that what appears to be the problem is not the problem. Meaning that it isn't necessarily the drinking that is the problem, it is the unresolved emotional conflict motivating the uncontrolled drinking that is the problem.

In APT, creating a core conflict formulation with the patient guides the treatment. So the patient and the therapist identify what presenting symptoms and other problems need to be resolved, along with their corresponding underlying emotional conflicts. Once emotional conflicts are identified, then a hypothesis is created paying careful attention to the origin of the conflict, especially if there is a link to attachment figures, that is, to significant family members. This link between past and present is essential to treatment as it offers the therapist and patient the opportunity to resolve "affect phobias" - that is, fears of feeling - and attachment ruptures from the past. For example, if a patient shies away from conflict due to being raised in a violent home, an APT therapist might help the patient regulate their anxiety and block their defenses so they can experience adaptive anger in the therapy, enabling them to feel more comfortable asserting themselves in their lives.

In APT, the premise is that instead of experiencing an adaptive affect and its expression, a person pulls back with an inhibitory affect that may activate a maladaptive defense, blocking connection with a sense of self and others. Therefore, a clinician can assume that a patient drinks to suppress an adaptive affect and its associated behaviors.

However, it isn't that simple, as affects are deeply embedded in our relationships. We feel joy with one another. We experience sadness together. We separate out of anger. We repair with love. So the role of the therapeutic relationship is vital in this reparative process as patients not only experience warded off affects through exposure and desensitization, but they do it with the therapist, therefore exposing themselves to closeness. Focusing on the emotional conflicts helps the therapist and patient structure treatment so as to deliver results in a timely fashion. That being said, the therapist must keep in mind that authentic relationships accept and honor all feelings between two people-like love, hate, grief, disappointment, joy, and sadness. So it is important for therapists to be accepting and tolerant of all emotions their patients are willing and able to experience with them through the process of treatment.

APT is an experiential dynamic model that uses exposure and desensitization to regulate inhibitory affects and prevent maladaptive defenses, so the patient can experience previously warded off adaptive affects and associated behaviors. Since the therapist and patient are working 
The Impact of Affect Phobia Therapy (APT) on Alcohol Use Disorders (AUD)-Evaluating Three Case Studies K.A.R. Osborn

Pragmatic Case Studies in Psychotherapy, http://pcsp.libraries.rutgers.edu

Volume 15, Module 3, Article 2, pp. 258-271, 01-09-20 [copyright by author]

together to resolve emotional conflicts that are deeply embedded in the past, it is common for them to work with complex feelings (like rage, guilt, grief, and love) that emerge in a transference relationship. My Frankl's (2020) case studies illustrate the connection between assessment and experiential interventions in APT, and the reader can obtain a deep sense of how this works through each case study.

\section{FRANKL'S CASE STUDIES}

Frank1, a doctoral-level licensed psychologist and psychotherapist in Stockholm, Sweden and a graduate of Linköping University and Uppsala University, is the creator of this study. As she explores whether or not APT can successfully treat AUD, the design and process of the study needs to be taken into account, as well as Frankl's skills as a clinician and researcher. From a scientific perspective, Frankl is a true pioneer, openly sharing and researching her clinical work with her colleagues to uncover whether, and if so, under what circumstances, the APT model can help decrease alcohol consumption in her three case studies.

The patients in Frankl's case studies - Carey, Michelle, and Mary — are all Swedish mothers in long-term relationships with mild-to-moderate symptoms of Alcohol Use Disorder (AUD) that started after the age of 30, and they have all sought treatment for their alcohol use for the first time. They participated in a study that Frankl and her colleagues designed so Frankl could analyze the process of treating patients with AUD using a 10-session version of APT. Frankl is the clinician who delivered the treatment and the researcher who studies the outcome.

\section{AUD Is Embedded in Close Family Relationships}

Carey, a 60 year old woman in her third marriage, feels guilty for her avoidant behaviors in her second marriage and how they have impacted her ability to be close to her deceased parents and her two sons. Michelle, a 44 year old woman, suffers from a lifelong sense of loneliness and insecurity due to her father's alcoholism and her mother's absence. She struggles professionally and relationally, and she feels guilty and ashamed for how her drinking has impacted her nine-year-old son. Mary, a 46 year old woman, has felt insecure and anxious since childhood due to her family's discomfort with emotions and conflict. Alcohol has lessened her social anxiety, yet she feels guilty and ashamed as she is drinking more and is unable to stop.

Thus, and as discussed above, for all three patients, emotional conflicts and associated affect phobias are importantly related to close family relationships. Specifically, all three patients hide their drinking from others due to their shame and guilt, and two out of the three patients (Michelle and Mary) are able to identify difficulties with their sense of self and others since childhood. As we review these cases, it is important to keep in mind three questions: Can APT be used with AUD patients? And if so, what is the recommended process of treatment? And how do we identify outcome?

\section{AUD and Affect Regulation}

Frankl has done a fine job of beginning this important discussion on the relationship between alcohol use and the dynamics of affect experience, expression, regulation, and inhibition 
The Impact of Affect Phobia Therapy (APT) on Alcohol Use Disorders (AUD)-Evaluating Three Case Studies K.A.R. Osborn

Pragmatic Case Studies in Psychotherapy, http://pcsp.libraries.rutgers.edu

Volume 15, Module 3, Article 2, pp. 258-271, 01-09-20 [copyright by author]

as set forth in the APT model. For example, based on Khantzian (1997, 2012), Frankl explains that alcohol abuse can be used as a

a means to relieve painful affects, to control affects when they are confusing, or to activate affects when they are absent, as well as, to cope with difficulties regarding self-esteem, relationships, and self-care (Frankl et al., 2020, p. 219).

Frankl draws our awareness to how multi-faceted alcohol use can be for a person, implying the importance of understanding the function and benefits of the behavior. In each case study, Frankl helps us understand the underlying emotional conflicts that drive the problematic drinking.

While there are hypotheses about each case that are viable and different from Frankl's, it is important for the reader to follow the course of treatment through Frankl's eyes in order to get a sense of how to operationalize the model and the complexity of unwinding the origin of an emotional conflict from a psychodynamic perspective.

For instance, Frankl describes how the three cases illustrate different ways in which alcohol functions. As one example, in Carey's case, Frankl hypothesizes that alcohol appears to be used as a defense against Carey's closeness with herself and others, and thus that Carey needs to be more self-compassionate and self-forgiving. Frankl is able to work through Carey's defenses by helping her more fully experience and express closeness within and outside of their therapeutic relationship, resulting in a very positive outcome. Consistent with APT theory, Carey's improvement in feeling and functioning parallel a decrease in her affect phobia on the Affect Phobia Test, being the only one of the three patients who ended the project with a score in the adaptive affective capacity range of the test.

\section{The Role of Feelings of Shame in AUD}

Frankl's case studies are invaluable as they help us begin to articulate what may be the specific emotional needs for the AUD population and how to address these needs in treatment. For instance, we see that shame plays a role in each case study: all three patients hide their alcohol use at the beginning of treatment and toward the end of treatment they are more transparent. This outcome may indicate that the treatment resulted in a decrease of shame as not only are the patients opening up in the therapy sessions to Frankl, but also outside of sessions.

Due to these indicators, it would make sense to develop another study on AUD and APT that focuses on decreasing the inhibitory and maladaptive affect of shame as it relates to alcohol consumption. Would treatment change and outcome improve if we were to explicitly focus on regulating shame related to drinking instead of decreasing alcohol consumption?

\section{Individualizing and Adjusting APT Treatment Based on Feedback from Ongoing Therapy}

As we look at her three case studies, we should pay close attention to Frankl showing us a compassionate, engaged, and positively-minded clinician, willing and able to adjust treatment as needed. In the case of Michelle, Frankl openly shares, 
The Impact of Affect Phobia Therapy (APT) on Alcohol Use Disorders (AUD)-Evaluating Three Case Studies K.A.R. Osborn

Pragmatic Case Studies in Psychotherapy, http://pcsp.libraries.rutgers.edu

Volume 15, Module 3, Article 2, pp. 258-271, 01-09-20 [copyright by author]

Michelle and I were both struggling with wanting the therapy to lead to change. This goal, though, had apparently been set too high. It seemed as if hope was achieved in most sessions, but the foundation for making real progress was too shallow. The focus of therapy, it was now clear needed to be on body awareness and on strengthening Michelle's capacity to tolerate feelings of anxiety (Frankl et al. 2020, p. 235).

In Frankl's assessment of her patients, we see her generosity of time, her interest, and her caring. And, as Frankl creates a core conflict formulation for each patient that is so thorough that it sometimes, I would suggest, exceeds the capacity of a ten-session treatment.

Frankl demonstrates her ability to adapt to the person she is sitting with rather than the manual she is working with, illustrating her commitment and determination to help her patients. For example, within her description of Session 3 of Mary's therapy, Frankl writes:

Early in the process I was realizing that the therapy had to have a focus other than defense and affect restructuring. Instead, in order to start reducing feelings of shame and guilt, I would have to first build trust and focus on lessening self-criticism (Frankl et al., pp. 239240).

\section{Frankl's Activation of Transference Feelings}

Frankl's powerful therapeutic presence activates transference feelings in all three cases, and we see how this dynamic propels Carey's treatment forward. On the other hand, for Michelle and Mary who were neglected in childhood, these transference feelings made treatment more complicated, requiring the need to identify achievable goals and to work more within the transference.

For Carey, Frankl's interventions are aligned with her core conflict formulation; and in Session 3, Frankl shifts from self-restructuring to self-other restructuring using the two-chair technique. Carey's 10-session treatment ends with positive results as Carey not only decreases her excessive alcohol consumption, but she also experiences increased closeness with herself and others.

For Michelle, a consistent focus on self-restructuring from an object relations perspective may have offered Frankl the support she needed to work with Michelle's emerging transference feelings. As Frankl wrote about Session 7:

I asked what she was longing for. Michelle said that she had a sense that she was alone and that she herself had to fix everything. She longed for support, to lie in someone's lap and be comforted. She experienced both a fear of letting a person get close and also the sorrow that there was no such person in her life who could console her. (Frankl et al, 2020, p. 234).

Perhaps if Frankl had more explicitly identified transference feelings by carefully noting inhibitory affect and maladaptive defenses emerging in therapy, this would have helped Frankl and Michelle to set more reasonable goals for treatment, allowing them to work together in building a foundation for healing in the future. 
The Impact of Affect Phobia Therapy (APT) on Alcohol Use Disorders (AUD)-Evaluating Three Case Studies K.A.R. Osborn

Pragmatic Case Studies in Psychotherapy, http://pcsp.libraries.rutgers.edu

Volume 15, Module 3, Article 2, pp. 258-271, 01-09-20 [copyright by author]

For Mary, similar to Michelle, her emotional conflicts stem from childhood neglect, suggesting the need for a longer course of treatment, as she drinks to soothe her aloneness and to calm her rage for feeling unloveable. In Session 7, Frankl is beginning to understand how vital working on Mary's defenses against closeness would be in this case.

I said that I was feeling tender feelings toward her, that I cared about her and wanted her to feel more relaxed and able to access with me the hurtful feelings. Thus the therapeutic work focused on making her feel secure, but I wondered if Mary was really able to benefit from the support offered due to her strong defenses (Frankl et al., p. 241).

Given more time, Frankl may have been able address Mary's inability to receive support from her therapist. Together they could have explored whether or not Frankl's care and kindness was eliciting unconscious anxiety and warding off closeness and related feelings. In this context, it could have been therapeutically productive if Frankl had initiated exposure and desensitization to closeness while at the same time noting Mary's anxiety and defenses in therapy. Frankl could have said something like, "I sense how hard it is for you to take in my positive regard," and processed this with Mary in terms of Mary's experience.

\section{The Issue of Sobriety Before Treatment}

It is important to keep in mind that traditionally in the field of short-term dynamic psychotherapy, it is recommended that patients experience one year of sobriety before engaging in an experiential-dynamic therapeutic process. In light of this, the research design Frankl and colleagues follow takes a risk in trying to help patients with active AUD and in evaluating whether or not the use of APT will decrease alcohol consumption.

Due to not requiring one-year sobriety before treatment, within the context of the APT model, Frankl is correct in all three cases by focusing in on self-restructuring. In addition, it would have been consistent with the model if Frankl had identified self-restructuring as the sole focus for each case, leaving herself open to working with affect phobias as they emerged, and shifting to self-other restructuring when needed, as she did with Cary.

\section{Activating Inhibitory Affects and Maladaptive Defenses}

Frankl is a skillful clinician as she seamlessly attunes to and cares for her patients, and her presence mobilizes inhibitory affects and maladaptive defenses with both Michelle and Mary. From the perspective of the APT model, I propose that it would have been helpful if Frankl had been more alerted to the impact of her relational presence on these two patients and had created a core conflict formulation that more closely linked feelings her patients were experiencing toward her and their link to past figures.

Fortunately in the case of Carey, Frankl is able to help Carey resolve her block to feeling positive emotions towards the self and closeness to others. In the cases of Michelle and Mary, it isn't so simple as they both suffered from neglect in their childhood and had to work through transference issues with Frankl and at home.

In the case of Michelle, she is plagued with guilt and is not only self-attacking, but is also threatened and devalued by her partner: 
The Impact of Affect Phobia Therapy (APT) on Alcohol Use Disorders (AUD)-Evaluating Three Case Studies K.A.R. Osborn

Pragmatic Case Studies in Psychotherapy, http://pcsp.libraries.rutgers.edu

Volume 15, Module 3, Article 2, pp. 258-271, 01-09-20 [copyright by author]

She experienced intense guilt feelings toward her partner and her child associated with her drinking (Frankl et al., p. 232).

If Frankl had addressed the link between guilt and self-attack as it relates to closeness towards others, perhaps Michelle may have been able to reach a deeper understanding as to how her alcohol consumption contributed to this dynamic.

In the case of Mary, from my clinical perspective, Frankl needed to address more fully Mary's fear of abandonment and how it was activated within the therapeutic relationship.

Perhaps through Frankl's three case studies, we are discovering that less emphasis should be placed on the therapist resolving an "affect phobia" per se when working with AUD; and that more emphasis should be placed on developing a core conflict formulation with the patient, remembering to be mindful of how this process may elicit complex feelings in the transference relationship. A correct formulation can cause a patient to feel truly seen for the first time, and this can be emotionally moving for both therapist and patient. It's important to compassionately honor this process and be accepting of all feelings, memories, and stories that may transpire.

We see how masterfully Frankl begins this process with Cary in the first session,

A core conflict started to form where positive feelings of the self and closeness to others had been linked to anxiety and guilt, which she avoided through excessive alcohol consumption and high levels of self-criticism. We both understood that Carey had used alcohol as a way of suppressing painful feelings (Frankl et al., 2020, p. 227).

In the case of Michelle, Frankl seems initially too focused on resolving the "affect phobia," missing opportunities to work with transference and projection toward Michelle's son, Michelle's partner, and Frankl. Unfortunately Michelle and Frankl place too much pressure on resolving too soon Michelle's conflict with anger/assertion, and Michelle arrives in Session 5 with a sense of failure as she is unable to approach her son. Frankl corrects this therapeutic rupture and explains,

She was not ready to be trained in expressing needs and wants explicitly (Frankl et al., 2020, p. 234).

In supervision, Frankl goes on to explain,

In consultation with my supervisor it became obvious that Michelle's defenses were still too strong for me to help her relinquish them and expose the feelings she was phobic about (Frankl et al., 2020, p. 234).

A parallel process emerges as both Frankl and Michelle place too much pressure on themselves, but Frankl makes a correction in Session 6, focusing on Michelle's sense of self and exploring projections. Frankl helps Michelle through visualization to successfully experience anger/assertion in session,

She felt her arms being strong, being able to carry the television, and she felt a sense of relief in her chest (Frankl et al., 2020, p. 234). 
The Impact of Affect Phobia Therapy (APT) on Alcohol Use Disorders (AUD)-Evaluating Three Case Studies K.A.R. Osborn

Pragmatic Case Studies in Psychotherapy, http://pcsp.libraries.rutgers.edu

Volume 15, Module 3, Article 2, pp. 258-271, 01-09-20 [copyright by author]

Regulating expectations is key within an exposure and desensitization model, and Frankl understands why the process was rushed,

Michelle and I were both struggling with wanting the therapy to lead to change. This goal, though, had apparently been set too high. It seemed as if hope was achieved in most sessions, but the foundation for making real progress was too shallow (Frankl et al., 2020, p. 235).

\section{Missing Some Moments of Connection}

In my view, in the cases of Cary, Michelle, and Mary, Frankl expected too much of herself and that pressure overshadowed some moments of connection that unfolded and needed to be addressed and processed as a part of treatment. For example, in the case study of Michelle, in Session 4, Frankl and Michelle are focusing on repairing a memory of an attachment failure with Michelle's father, which emerged in the previous session. Frankl then writes:

I prompted her [Michelle] to formulate the words she wanted to say to her son, and asked her how she felt when saying them. Instead, Michelle started to talk about how her partner had told her that she would lose her son due to her drinking. This was her greatest fear. I asked Michelle to describe her activities and her contact with her son, and also touched upon Swedish social welfare laws concerning parental rights. In my effort to comfort Michelle, I lost track of the focus of the therapeutic work. Still, at the end of the session Michelle was full of faith that she would have the courage to talk with her son (Frankl et al., 2020, p. 233).

While Frankl is harsh with herself for not following the APT manual, what transpires is at the heart of psychotherapy. We not only witness a moment of meeting, but we also witness an intergenerational healing, a reparative moment. That is, in the therapy relationship itself, Frankl offers the helpful advice and emotional support to Michelle that Michelle did not receive in childhood from her own mother; and through the two-chair technique, Michelle offers her son what he didn't receive in his childhood from his own mother. All three figures - the therapist, the patient and the patient's son-go back in time and repair what was missing. Frankl goes into a messy memory and returns with a new ending. In other words, by going beyond the manual, Frankl supports Michelle in a healthful way, meeting Michelle's needs and solidifying their working alliance.

\section{An Example of Conducting the Two-Chair Technique Skillfully}

In her work with Carey, Frankl's curiosity mixed with her capacity for detail stands out as she asks Carey, in Session 3, to give examples of how she relates to others and moves into a two-chair technique with positive results,

I followed Carey's process closely in the exercise, asking what Carey felt and what she saw in her mother's eyes, prompting Carey to address her mother verbally or with a focus on Carey's emotions, when it was need to make the process proceed. Carey was filled with feelings of grief. When she was asked to sit in the other chair and take the position of the mother, Carey was filled with feelings of love, and inside her head she heard her mother express loving feelings toward her (Frankl et al., 2020, p. 227). 
The Impact of Affect Phobia Therapy (APT) on Alcohol Use Disorders (AUD)-Evaluating Three Case Studies K.A.R. Osborn

Pragmatic Case Studies in Psychotherapy, http://pcsp.libraries.rutgers.edu

Volume 15, Module 3, Article 2, pp. 258-271, 01-09-20 [copyright by author]

The exercise resulted in a transformed feeling of presence and love, as Carey reported at the beginning of Session 4:

On coming into session 4, the first thing Carey told me was that she had experienced a transformed feeling of presence and love in regard to her parents in her current life. She had fantasized talking to them during the week, and she felt that guilt had been cleared away from the relationship between them (Frankl et al., 2020, p. 228).

Thus this was a deeply intimate moment where Frankl offered Carey the loving attention she longed to have received from her mother. Below I describe the micro-process analysis technique of "Achievement of Therapeutic Objectives" (ATOS) coding. I suggest that if Frankl had used this coding in her sessions, it would have assisted in seeing the complex dynamics that were revealing themselves in Session 3 through using the two-chair technique.

\section{THE NEED TO AUGMENT FRANKL'S NARRATIVE ANALYSIS WITH USE OF THE "TEN-SESSION SUMMARY FORM"}

In APT, it is important to never lose sight of the presenting problems and corresponding emotional conflicts, and so it is recommended that APT therapists use the Ten-Session Summary Form, shown in Appendix 1. As can be seen, the form guides the clinician, every 5 sessions, in reviewing the patient's diagnosis, target problem(s), and core conflict(s) in the context of the main themes and predominant affects of the previous sessions. The form thus helps both patient and therapist stay focused on their therapeutic objectives, tracking adaptive affect exposures from session to session and adjusting diagnosis at Session 5 and Session 10. The Ten-Session Summary Form helps regulate both the therapist's and patient's expectations and assists in redirecting treatment if necessary, always identifying achievable therapeutic objectives. If Frank had used this form then it would have helped her be more aware of when focus shifts from selfrestructuring and self-other restructuring and feelings like guilt and anger.

\section{THE NEED TO AUGMENT FRANKL'S NARRATIVE ANALYSIS WITH MICRO-PROCESS ANALYSIS}

My recommendations for further study with AUD using APT would be to maintain the 10 -session structure and in addition to introduce the use of the below-described "Achievement of Therapeutic Objectives Scale" ("ATOS" Scale), in conjunction with analyzing the video segments of each session. I also think the use of the Ten-Session Summary Form would not only be helpful for collecting data session to session, but to also help patient and therapist stay focused on the presenting issues, the emotional conflicts, the affect exposures, and whether or not change is occurring by session 5. For instance, in the case of Carey, Frankl describes what treatment interventions were used that contributed to the positive outcome, but we have no transcript or ATOS scores to substantiate her conclusions. What defense did she block? In what session? Toward what feeling? Also, the addition of more clinicians and a team of ATOS coders could help each clinician identify session to session what appears to be working with the patient and what work needs to be done.

To operationalize the basic concepts in APT as defined by McCullough and her colleagues (McCullough et al., 2003), McCullough et al. (2004) developed the ATOS Scale. 
The Impact of Affect Phobia Therapy (APT) on Alcohol Use Disorders (AUD)-Evaluating Three Case Studies K.A.R. Osborn

Pragmatic Case Studies in Psychotherapy, http://pcsp.libraries.rutgers.edu

Volume 15, Module 3, Article 2, pp. 258-271, 01-09-20 [copyright by author]

Specifically, ATOS ratings are made separately for the client and therapist and are coded from 10 minute segments of video-recorded sessions. In terms of content, ratings are made of the presence of Activating Affects (AA codes), which involved operationalization of bodily signs of intensity and duration of experiencing the arousal of adaptive affects, like positive feelings toward the self, grief, anger/ self-assertion, pride and closeness. Also parallel ratings are completed for Inhibitory Affects (IA codes) which operationalize affects like pain, guilt, disgust and anxiety.

In addition the ATOS captures two composite codes based on a rating of whole sessions, both of which are excellent operationalizations of the types of psychological health that are the goal of APT. The first is the Sense of Self (SoS code) that measures

the compassionate and realistic quality of patients' self-descriptions ... based on patients' verbal report of their attitude and acts of kindness toward themselves as well as on patients' ability to hold both positive and negative aspects of the self in balanced awareness, to be affirming of one's own wants and needs without reacting with self-attack, self-negation, or negative self-statements. Additionally, ratings are based on patients' ability to have positive self-regard without it being inflated and grandiose (Berggraf, 2014, p. 249).

The second measure of psychological health is the Sense of Other (SOO code) that measures

the patient's self-description of his or her level of compassion, realism, trust in others, and ability to be affirming of other's needs and wants. The scale further measures the level of adaptive and realistic images of other people's positive and negative qualities and the integration of these images, the ability to hold both the positive and negative aspects of the others in a balanced awareness without reacting with naivete, idealization/devaluation, distrust, or projection. In addition, ratings are based on a patient's ability to tolerate conflicts and maintain the ability to set limits around destructive qualities in others, not tolerate abuse or receive undeserved devaluation from others (Berggraf, 2014, p. 249-250).

ATOS patient ratings are an integral aspect of the APT model, such that clinicians are trained to not only watch the process of psychotherapy, but to also code it in order to determine the patient's capacity to absorb therapeutic interventions. As described above, in Session 4 of Frankl's case study with Michelle, Frankl openly shares her distress for "going off the grid" from the APT manual, but I suggested an alternative, positive perspective. As I tell my trainees, don't tell me what you're doing, don't tell me how you are doing it, just press play on the videotape and let's look at the impact. Did it work with this client in this moment in this situation?

So what do we expect clinicians and researchers to see when reviewing video-segments of their own psychotherapy sessions or sessions of others with the ATOS Scale? We hope to answer the following types of questions.

- Is the patient aware of her/his defenses? If so, how well? Can the patient see their defenses on their own or do they need prompting from the therapist?

- How motivated is the patient to give up her/his defenses? 
The Impact of Affect Phobia Therapy (APT) on Alcohol Use Disorders (AUD)-Evaluating Three Case Studies K.A.R. Osborn

Pragmatic Case Studies in Psychotherapy, http://pcsp.libraries.rutgers.edu

Volume 15, Module 3, Article 2, pp. 258-271, 01-09-20 [copyright by author]

- How much anxiety is the patient experiencing in session?

- What adaptive affects is the patient experiencing in session?

- Is the patient experience new learning?

- Is there any change in the patient's Sense of Self?

- Is there any change in the patient's Sense of Others?

Since one can only code one adaptive affect at a time, clinician/researchers typically choose to code the affect that activates the most anxiety and resistance. For instance, if a patient is smiling and changing the subject while talking about the death of a loved one, the clinician/researchers would first code for grief in order to identify the level of anxiety and resistance in the face of this affect. Generally, for as informed a view as possible, the more coders available, the better.

An example of the usefulness of the ATOS in empirically validating parts of APT theory is a study by Berggraf et al. (2014) in which 947 psychotherapy videotapes (out of a total of 2000) were rated using the ATOS system. The videotapes were associated with the therapy of 47 patients diagnosed with DSM-III-R Cluster C personality disorders (primarily Avoidant, Obsessive-Compulsive, and/or Dependent ). Half were randomly assigned to APT therapy, and half to cognitive therapy. In both the APT and cognitive therapy groups, the ATOS data confirmed one of the major hypotheses of APT theory, namely, that experiencing higher levels of activating affects and lower levels of inhibiting affects was associated with higher levels of psychological health, as reflected on the level of Sense of Self ( $\mathrm{SoS})$ and Sense of Other (SoO) codes. Specifically the findings were:

Patients with better ability to experience AA [Adaptive Affects] at the start of therapy displayed significantly higher SoS and SoO across sessions compared with other patients. Patients who experienced higher levels of IA [Inhibitory Affects] at the start of therapy displayed lower levels of SoS across sessions. A patient experiencing more AA than usual for him/her self within a session predicted an increased level of SoS and SoO at the next measuring point. There were no different change patterns in the 2 treatment groups. Results suggest that focus within therapy sessions on increasing patients' AA can help facilitate change in SoS and SoO toward more compassionate and realistic quality (Berggrah et al., 2014, p. 246).

Over time, APT researchers developed an ATOS-Therapist (Donvoan, Osborn \& Rice, 2016) ratings version so that they could more easily identify a therapist's capacity: to identify defenses, to motivate the patient for change, to regulate a patient's anxiety, to expose adaptive affect, and to point out new learning. In my view Frankl would have been much more compassionate with herself if she had coded her video segments with the ATOS-Therapist ratings as she would have seen more easily in what ways she was and was not meeting her therapeutic objectives, and would have understood how to redirect herself (in a positive way) as she needed to in the case of Michelle. In training, my colleagues and I have discovered the ATOS-Therapist Scale to be very helpful, especially in identifying therapist affect phobias - that 
The Impact of Affect Phobia Therapy (APT) on Alcohol Use Disorders (AUD)-Evaluating Three Case Studies K.A.R. Osborn

Pragmatic Case Studies in Psychotherapy, http://pcsp.libraries.rutgers.edu

Volume 15, Module 3, Article 2, pp. 258-271, 01-09-20 [copyright by author]

is, when a therapist avoids a specific affect in a therapy session and unknowingly sabotages the process of treatment. A classic example is when a patient is clearly sad and about to tear up and the therapist changes the subject. The ATOS-Therapist ratings help a supervisor to understand in what areas a therapist might need additional training or support.

APT trainers and supervisors emphasize the use of micro-process analysis in the individual clinical case through the use of observation measures like ATOS. In My Frankl's (2020) cases of Carey, Michelle and Mary, the presentation of detailed transcripts with ATOS coding would have added another, important dimension of richness and insight into the narrative analysis that Frankl presents.

In particular, ATOS coding is very helpful in cases that are not responding to treatment as expected. For example, in Frankl's case of Mary, the ATOS could have revealed in a more precise and timely way Mary's difficulties in motivation.

\section{CONCLUSION}

In sum, Dr. My Frankl has made a significant contribution to the APT clinical literature by openly, sensitively, carefully, and thoughtfully conducting and documenting three cases of middle-aged women with mild to moderate Alcohol Use disorder. Frankl has identified concrete ways in which a 10-session APT therapy can, on the one hand, be clearly successful in dealing with certain types of clients like Carey with mild to moderate Alcohol Use Disorder (AUD); and, on the other hand, generally be unsuccessful in treating other types of clients like Michelle and Mary with similar demographic and similar AUD conditions as Carey. In this commentary I have suggested two assessment approaches drawn from the APT practice community- the use of the micro-analysis assessment technique of ATOS coding and the use of the Ten-Session Summary form (see Appendix 1) - by which the clinical therapeutic process in cases like Carey, Michelle, and Mary could have been enhanced.

\section{REFERENCES}

Berggraf, L., Ulvenes, P.G., Oktedalen,, T., Hoffart, A., McCullough, L., Stules, T., \& Wampold, B.E. (2014). Experience of affects predicting sense of self and others in shortterm dynamic and cognitive therapy. Psychotherapy, 51, 246-257.

Donovan, J., Osborn, K., \& Rice, S. (2016). Paraverbal communication in psychotherapy: Beyond the words. Rowman \& Littlefield Publishers

Frankl, M., Wennberg, P., Berggraf, L., \& Philips, B. (2020). Affect Phobia Therapy for mild to moderate Alcohol Use Disorder: The cases of "Carey," "Michelle," and "Mary."

Pragmatic Case Studies in Psychotherapy 15(3), Article 1, 214-257. Available: http://pcsp.libraries.rutgers.edu/

Khantzian, E. J. (1997). The self-medication hypothesis of substance use disorders: A reconsideration and recent applications. Harvard Review of Psychiatry, 4, 231-44. http://doi.org/10.3109/10673229709030550

Khantzian, E. J. (2012). Reflections on treating addictive disorders: A psychodynamic perspective. The American Journal on Addictions/American Academy of Psychiatrists in Alcoholism and Addictions, 21, 274-279. 
The Impact of Affect Phobia Therapy (APT) on Alcohol Use Disorders (AUD)-Evaluating Three Case Studies

K.A.R. Osborn

Pragmatic Case Studies in Psychotherapy, http://pcsp.libraries.rutgers.edu

Volume 15, Module 3, Article 2, pp. 258-271, 01-09-20 [copyright by author]

McCullough, L., Kuhn, N., Andrews, S., Kaplan, A., Wolf, J., \& Hurley, C. (2003). Treating Affect Phobia: A manual for Short-Term Dynamic Psychotherapy. New York: Guilford Press.

McCullough, L., Kuhn, N., Andrews, S., Valen, J., Hatch, D., \& Osimo, F.(2004). The reliability of the Achievement of Therapeutic Objectives Scale: A research and teaching tool for psychotherapy. Journal of Brief Therapy, 2, 72-90. 
The Impact of Affect Phobia Therapy (APT) on Alcohol Use Disorders (AUD)-Evaluating Three Case Studies K.A.R. Osborn

Pragmatic Case Studies in Psychotherapy, http://pcsp.libraries.rutgers.edu

Volume 15, Module 3, Article 2, pp. 258-271, 01-09-20 [copyright by author]

\section{Appendix 1. Ten-Session Summary Form}

\begin{tabular}{|c|c|c|c|c|}
\hline \multirow{5}{*}{$\begin{array}{c}\text { TEn-SESSION SuMMARY Form } \\
\text { Psychotherapy Research Program at HMS } \\
\text { Leigh McCullough, Ph.D. (3/05) }\end{array}$} & Session Number: & 1 & 5 & - 0 \\
\hline & Session Date: & & & \\
\hline & Axis I: & & & \\
\hline & Axis I: & & & \\
\hline & Axis IIA: & & & \\
\hline \multirow{4}{*}{ Patient Name/Initials: } & Axis IIB: & & & \\
\hline & Axis IIC: & & & \\
\hline & Axis III: & & & \\
\hline & Axis IV: & & & \\
\hline \multicolumn{5}{|l|}{ Target Problems: (One to three examples) } \\
\hline 1) & TP1 Rating: & & & \\
\hline 2) & TP2 Rating: & & & \\
\hline 3) & TP3 Rating: & & & \\
\hline \multicolumn{5}{|l|}{ Core Conflict(s): } \\
\hline 1) & CC1 Rating: & & & \\
\hline 2) & CC2 Rating: & & & \\
\hline 3) & CC3 Rating: & & & \\
\hline 4) & CC4 Rating: & & & \\
\hline
\end{tabular}

\begin{tabular}{|c|c|c|c|c|}
\hline Sess. & Date & MaIN Theme(s) OF Session & $\mathrm{CC}$ & $\begin{array}{l}\text { Rate } \\
1-10\end{array}$ \\
\hline-1 & & & & \\
\hline-2 & & & & \\
\hline-3 & & & & \\
\hline$-{ }^{4}$ & & & & \\
\hline-5 & & & & \\
\hline$-^{6}$ & & & & \\
\hline-7 & & & & \\
\hline-8 & & & & \\
\hline-9 & & & & \\
\hline$-^{0}$ & & & & \\
\hline
\end{tabular}

$\mathrm{CC}=$ Core Affective Conflict focused on during session. List predominant affect and rate 1-10. (10= High) 